\title{
The Interrelationship among Language Use, Linguistic Competence, and Higher Order Skills
}

\section{HAZIM TAISIR DAYIJ ALKHRISHEH ${ }^{1}$, FAILASOFAH ${ }^{2}$, AND TAISIR ALKHRISHEH ${ }^{3}$}

\begin{abstract}
This research aims to investigate the relationship amongst three concepts: language use, linguistic competence, and critical thinking. Pedagogical and cognitive aspects of language learning are evident in the implications of this research concerning how thought influences learning, and how learning influences thought. The sample of the study consisted of 52 students from Mutah University in Jordan enrolled in the BA program in the department of English language and literature. The instruments used in the study included the LEAP-Q to measure the multilingual level of participants to determine language use, a critical thinking test to measure the participants' level of reasoning, and a TOEFL proficiency test to measure the participants' level of linguistic competence. The findings show significant positive correlations between language use and critical thinking, between linguistic competence and critical thinking, and between language use and linguistic competence. We conclude that language use enhances the linguistic abilities and possibly enhances the cognitive capabilities of the participants. We recommend encouraging students to use the second language inside and outside the classroom to enhance their linguistic and cognitive abilities.
\end{abstract}

\section{Keywords}

Higher order skills, language use, linguistic competence

\footnotetext{
1. PhD student at Multilingualism Doctoral School, the University of Pannonia, Hungary; $\underline{\text { hkhresha@yahoo.com }}$

2. PhD student at Multilingualism Doctoral School, the University of Pannonia, Hungary and Faculty member at Faculty of Teacher Training and Education, Universitas Jambi, Jambi, Indonesia; failasofah@unja.ac.id

3.Amman Arab University, Jordan; tkhrisheh@yahoo.com
} 


\section{IRJE | Indonesian Research Journal in Education | | Vol. 5 | No. 1|June | Year 2021|}

\section{Introduction}

Jordanian students often believe that using English as a second language outside the classroom compromises their national and local identity. However, using a second language proves to be important, not only in enhancing linguistic skills, but also social and cognitive abilities (see Alladi et al., 2013; Bialystok et al., 2007). The main purpose of the study is to encourage students to use the second language (i.e., English) inside and outside the classroom in order to improve their linguistic, social, and cognitive skills. The fact that language use enhances linguistic skills is apparent in second language settings in which the learner is accommodated in an environment where the second language is practiced on a daily basis. The daily exercised linguistic skills are carried over from exercising social and cognitive skills required in accomplishing a successive chain of communicative engagements for different purposes. All these skills are somehow linked due to the existence of similar skills shared amongst them such as making analysis and interpreting information. These skills are cognitive in nature (higher order skills), yet they have linguistic and social beneficiary dimensions. The literature on higher order skills and especially on critical thinking mostly discusses both: the influence of critical thinking on learning (in general), and its influence on language learning in particular (see Fábián, 2015; Meiramova, 2017; Rezaei et al., 2011; Shirkhani, \& Fahim, 2011). According to Cottrell (2017), critical thinking builds up the skills needed to succeed in a changing world especially when people have to compete against each other to prove their worth. Learning the skills needed to qualify individuals for life is a common demand given that the world no longer depends (solely) on labor. The pedagogical implications of past studies indicate that critical thinking is crucial in learning (in general) and also crucial in language learning and language assessment.

However, few studies show that there is a cognitive advantage for using more than one language (see Alladi et al., 2013; Bialystok et al., 2004; Bialystok et al., 2007; Kirk et al., 2013). The implications of these studies indicate that language use also influences the cognitive abilities of the subjects. This research aims to investigate the relationship between three concepts: language use (which is determined by the multilingual level of the participants and measured by the LEAP-Q), linguistic competence (measured with a TOEFL proficiency test), and higher order skills (measured by a critical thinking test) in order to see which variables have stronger correlations. The significance of the study arises to address the issue of language use. In simple words, this study aims to clarify if exposing students to more second language input proves to be associated to linguistic capabilities and higher order skills. The study magnifies the importance of conversations' engagements in shaping the learner's mind in a world where migration is becoming a more common trend. Immigrants need to communicate with natives and it seems that this communication aids them in attaining linguistic and social knowledge using different cognitive techniques. The previous literature focuses little on the impact of language use on critical thinking. Exploring the relationship between the critical thinking and language use is a significant starting point for researchers who want to conduct longitudinal studies to investigate the impact of language use on higher order skills if language use and critical thinking are strongly and significantly related. Our main objective is to show how using a language on a regular basis inside and 


\section{IRJE | Indonesian Research Journal in Education | | Vol. 5 | No. 1|June | Year 2021|}

outside the classroom might benefit students in linguistic and cognitive terms. Accordingly, we are conducting a correlation analyses to detect the degree of closeness of one variable to another as presented in our research questions below:

1. What is the relationship between language use and critical thinking?

2. What is the relationship between the linguistic competence of students and critical thinking?

3. What is the relationship between language use and linguistic competence?

Following the research questions, our hypotheses below are formed to answer the research questions respectively:

1. The multilingual level of students, which is based on language use and measured by the LEAP-Q, will positively and significantly correlate to their score in the critical thinking test.

2. The linguistic competence, which is based on the proficiency test score, will positively and significantly correlate to their score in the critical thinking test.

3. The multilingual level of students will positively and significantly correlate to their linguistic competence.

\section{Literature review}

\section{Language use in multilingual settings}

People often use more than one language and sometimes more than two languages as their increased mobility demands for different reasons including their occupation, education, or immigration. Therefore, in order to initiate and maintain communication with other people in different languages, there is a need to learn a second or even a third language. Second language acquisition and learning has been the topic of interest for researchers for many years. The use of two (or more) languages or dialects on people's everyday life, according to Grosjean (2002), has been undeniably widespread and become the norm in the world recently. This practice is known as bi- or multilingualism. He mentioned that there are some reasons causing languages into contact and hence foster bior multilingualism such as migration of various kind (economic, education, political, religious), nationalism and federalism, education and culture, trade and commerce, and intermarriage. However, the benefits of being a bilingual have been debated for many years. Some arguments and researches show that bi- or multilingualism gives some positive effects for an individual. On the other hand, it is also believed that being a bi- or multilingual could not provide any form of cognitive benefits.

Basically, the linguistic systems are fluctuated in children and adults by which the use of and the proficiency in two languages or more may alter based on the frequency of the language being used for their own interest or for other users in their communication (Weinreich in Bhatia, 2013). Several psycholinguistic studies have shown that bi- and multilingualism can result in linguistic and cognitive advantages such as some research on the cognitive advantages of bilingualism done by Bialystok since 1991 to 2009. de Bot (2017) added that bi-or multilingual heavy task in monitoring the situation to select the appropriate language is an exercise for the speakers' brain. This exercise develops particular traits in the 


\section{IRJE | Indonesian Research Journal in Education | | Vol. 5 | No. 1|June | Year 2021|}

speakers' general skills domain which are transferred from the language domain. In other words, the use of multiple languages leads to the activation of skills that also affect non-linguistic skills. Another finding explained by Cook (2005) is that multilingual language users differ from monolingual language users in many considerable ways. Their flexibility in their communication increases language awareness and it leads to better attitudes towards other cultures.

Furthermore, Jessner, (2008) mentioned that being multilingual means having enhanced linguistic knowledge and experience in different languages, which may lead to different and possibly more efficient qualities in the multilingual learner and user. In the process of communicating using two or more languages, multilingualism activates some particular skills and abilities that are absent in most of the monolingual speakers' minds. One of the skills developed by multilingual learners as the crucial language strategies is metalinguistic awareness (Jessner \& Török, 2017). That skill is important for learners in their process of decoding different language grammar structure (Kemp in Jessner \& Török, 2017). Furthermore, Jessner (in Herdina \& Jessner, 2002) stated that the learners' enhanced development of metalinguistic awareness as multilingual speakers might influence his/her language learning skills and language management skills. It would be a crucial skill because in language acquisition, the language learning process is often interrupted by the process of overcoming different linguistic systems that exist in the new language.

Metalinguistic awareness has been defined as the ability to objectify language and dissect it as an arbitrary linguistic code independent of meaning. It is the ability to look at language as a thing; to evaluate language as a process or even a system; and to exercise successfully in using language (Nixon, 2013) which play important role in the development of language learning strategies in language learners and users (Jessner, 2008). Those strategies exist at a particular stage in language learning process in a form of mental activity (Ellis in Jessner, 2008) which a number of them are also found by Naiman et al. (in Jessner, 2008) in their study. They are an active learning approach, realization of language as a system, realization of language as a means of communication, handling of affective demands and monitoring of progress. Expert learners in their study showed a superior competence in shifting strategies and reconstructing their internal representations of the linguistic system. Critical literacy awareness is the process of thinking critically to analyse and critique the information of social, cultural, and political power that one received. That awareness is needed when people interact with texts as medium of our communication. We have to interpret and make proper meaning on them in order to be successful in our exchange.

Multilinguals flexibility in their communication increases language awareness and it leads to better attitudes towards other culture. One of the skills developed by multilingual learners as the crucial language strategies is metalinguistic awareness (Jessner \& Török, 2017). That skill is important for learners in their process of decoding different language grammar structure (Kemp in Jessner \& Török, 2017). Furthermore, Jessner (in Herdina \& Jessner, 2002) stated that learner's enhanced development of metalinguistic awareness as a multilingual speaker might advance his/her language learning skills and language management skills. It would be a crucial skill since in multilingual acquisition the language learning process is often interrupted by another new language. 


\section{IRJE | Indonesian Research Journal in Education | | Vol. 5 | No. 1|June | Year 2021|}

\section{Critical thinking as a cognitive asset for real-life preparation}

According to the previous review, the cognitive capacity build in the multilinguals encourages them to be critical thinkers who are also characterized with some essential skills and abilities in communication. In her multilevel model approach, Fabian (2018) emphasizes that at the individual level, critical thinking is the set of intellectual skills, abilities and dispositions. Fabian indicates that researchers agree that critical thinkers should be capable of utilizing inductive and deductive reasoning, making decisions or solving problems, or asking and answering questions for clarification. Additionally, certain dispositions are necessary as the indicators of critical thinking, such as open mindedness, fair-mindedness, the propensity to seek reason, inquisitiveness, flexibility and respect for others' opinions. Critical thinking refers to an ability to analyse information, to determine the relevance of information gathered and then to interpret it in solving the problems which requires high-level thinking; it involves the process of analysis, evaluation, reasonableness and reflection.

The literature on critical thinking traces back the phenomena to three main academic disciplines: psychology, philosophy, and the field of education (Lewis \& Smith, 1993; Sternberg, 1986). The philosophical discipline developed the critical thinking approach to fit their perspective which is more focused on hypothetical critical thinking. Sternberg (1986) has reported that the philosophical school puts more emphasis on the characteristics of critical thinkers under certain conditions and circumstances. Facione (1990), for instance, describes the critical thinker as an open-minded, flexible, well-informed individual. Paul (1992b) discusses the phenomena of critical thinking in the context of "perfections of thought" (p. 9). He described critical thinking as "the art of thinking about your thinking while you are thinking ..." (Paul, 1992a, p. 643). However, the literature on critical thinking provides much more clear, concise, and concrete descriptions and definitions of critical thinking (Burden \& Byrd, 1994; Halpern, 1996; Pascarella \& Terenzini 1991; Ennis, 1962). Moreover, the psychological school differs from the philosophical school in two ways. The first is concerned with the main scope of the psychological approach which focuses on the actions of critical thinkers. In other words, it focuses on what skills and abilities are usually practiced by critical thinkers (Lewis \& Smith, 1993). Basically, the behaviour of critical thinkers is the main concern of the psychological school whereas the philosophical school puts more emphasis on the characteristics and qualities of critical thinkers. The second difference is the focus on what people think measured against what they should think in certain conditions (Sternberg, 1986). The psychological school differs from the philosophical school in presenting what aspects of critical thinking should be apparent. Furthermore, the field of education has also had its share of critical thinking especially in the teaching and learning aspects of critical thinking such as Benjamin Bloom's taxonomy for information processing skills (Bloom, 1956). The advantage form which the educational school draws its benefits is the fact that it is based on years of experience of classroom practices (Sternberg, 1986). However, the lack of clarity regarding their conceptual framework is evident in their instructional guides (but not the instruction strategies) and assessment of critical thinking (Sternberg, 1986). 


\section{IRJE | Indonesian Research Journal in Education | | Vol. 5 | No. 1|June | Year 2021|}

Some researchers have defined critical thinking in terms of skills (Burden \& Byrd, 1994; Ennis, 1962; Halpern, 1996). Others have defined critical thinking in terms of complying to reasonable logic (Pascarella and Terenzini, 1991; Simon \& Kaplan, 1989; Stahl \& Stahl, 1991). Even further, Bloom's taxonomy associates critical thinking to other higher order skills including Knowledge, Comprehension, Application, Analysis, and Evaluation (Bloom, Engelhart, Hill, \& Krathwohl, 1956). Despite the differences between researchers and the three schools of thought, there is an agreement amongst them regarding certain aspects of critical thinking. The aspects of agreement include analysis, using inductive or deductive reasoning to make inferences, judging or evaluating, and decision making or problem solving (Ennis, 1985; Facione, 1990; Halpern, 1998; Lipman, 1988; Willingham, 2007).

Furthermore, there is a wide agreement amongst researchers that concerns background knowledge. Most researchers agree that demonstrating higher order skills requires the individual's attention to background knowledge (Case, 2005; Kennedy et al., 1991; Willingham, 2007). Facione (1990) argues that domain specific knowledge is crucial in practicing reasonable judgment. However, there is a disagreement amongst researchers regarding the extent of domain specific knowledge. On one hand, there are those who argue for the generalized teaching of critical thinking across domains (Halpern, 2001). On the other hand, there are those who argue that thinking critically within a specific domain is more efficient (Willingham, 2007). Bailin (2002) points out that even at the specific skill level such as interpretation, the skill tends to vary across domains due to the different contexts that require different thinking. There are also those who argue that critical thinking is evident in both, general and domain specific areas. According to Ennis (1989), critical thinking includes both deductive and inductive reasoning. Ennis argues that some domains require deductive reasoning more often whereas other domains require inductive reasoning more often. Ennis further argues that both types of reasoning are usually practiced in social sciences. Even further, Ennis argues that a certain degree of subjectivity is acceptable in certain areas such as art.

Moreover, Facione (1990) argues for another area of agreement amongst researchers regarding dispositions. Facione (2000) refers to dispositions as habits of the mind that determine how one acts in predictable yet malleable ways. These dispositions are respect for others' opinions, the desire to be well informed, flexibility, the desire to seek reason, inquisitiveness, open mindedness, and fair mindedness. According to Facione (2000), critical thinking includes both, skills and dispositions. However, there is a disagreement on whether these dispositions are major or complementary aspects of critical thinking. On one hand, those who argue for dispositions as a major aspect hold that an individual who has the dispositions to think critically but chooses not to, is a critical thinker. On the other hand, those who argue for dispositions as a complementary aspect hold that ethical standards must be fulfilled when thinking in a critical manner. According to Facione (1990), an individual that does not follow the ethical standards in critical thinking is not a critical thinker.

There is a further area of disagreement amongst researchers regarding the spontaneous transferability of critical thinking. On one hand, there are researchers who argue that critical thinking skills are transferable from one domain to another. On the other hand, there are researchers who argue that critical thinking transferability is not feasible. 


\section{IRJE | Indonesian Research Journal in Education | | Vol. 5 | No. 1|June | Year 2021|}

Research in that area shows mixed results. Halpern (2001), for instance, reports a successful transfer in his study for his students from one domain to another. Nickerson (1988), on the other hand, reports mixed results to conclude that transferability seems to depend on what is taught and how it is taught. In other words, it depends on the distance of the transfer (Ennis, 1989). Distance refers to whether transfer is to be passed within the same or within a different domain. Transferring the skills to an entirely different domain seems to be more difficult to achieve than transferring the skills within the same or a similar domain. Moreover, the philosophical approach seems to emphasize passing criteria in addition to skill (Paul, 1992). According to Paul, these criteria include: fairness, significance, clarity, accuracy, precision, completeness, depth, logic, consistency, specificity, and relevance. The philosophical school puts even further emphasis on passing the criteria in an explicit manner (Paul, 1992).

Critical thinking has several relations to other concepts including metacognition, motivation, and creativity. Metacognition refers to one's own awareness and control over thought (Martinez, 2006). Some researchers see critical thinking as part of metacognition, whereas others see critical thinking as a concept holding metacognition as one of its components (Kuhn, 1999; Willingham, 2007). According to Kuhn (1999), critical thinking is a form of metacognition, which includes metacognitive knowing (thinking that depends on declarative knowledge), meta-strategic knowing (thinking that depends on procedural knowledge), and epistemological knowing (how knowledge is produced). On the other hand, Willingham (2007) argues that critical thinking includes applying strategic skills at the right time. Applying strategic skills requires strategic knowledge which is part of metacognition. Moreover, Facione (2000) views motivation as a precondition for applying critical thinking skills and abilities. Facione (2000) pointed at dispositions as the motivation that drives individuals to apply critical thinking. Motivation is seen as a base without which, critical thinking cannot be applied. Unmotivated subjects mostly won't exhibit critical thinking capabilities. Finally, substantial research links critical thinking to creativity (Bailin, 2002; Ennis, 1985). Bailin (2002) views creativity as a necessary condition for critical thinking. The link between critical thought and creativity comes from the fact that critical thinking requires generating intellectual products which, in turn, is linked to creativity. Being critical regarding the quality of the intellectual products enhances creative thinking.

Finally, not only adults exhibit critical thinking capabilities. Children also show critical thinking products including reasoning (Willingham, 2007). Kennedy, et al. (1991) discusses how critical thinking improves with age. The existence of critical thinking abilities in children is evident in the fact that it improves with aging. The authors argue that the only cause for children's failure to demonstrate critical thinking capabilities is attributed to the lack of background and content knowledge needed to engage in a task. Moreover, several studies reported children to have judgmental products to differentiate the credibility of various sources of information and topics (Koenig \& Harris, 2005; Lutz \& Keil, 2002). Lutz and Keil (2002) for instance found that children will find a mechanic's opinion regarding car trouble is more credible than a doctor's opinion for car trouble. Furthermore, Facione (1990) in pointing out to the APA Delphi report views a suggestion to include the instruction of critical thinking to all school levels including kindergarten and early stages in addition to junior high or high school levels. 


\section{IRJE | Indonesian Research Journal in Education | | Vol. 5 | No. 1|June | Year 2021|}

\section{Methodology}

\section{Research design, site, and participants}

This research was a cross-sectional correlational case study that relied more on quantitative analysis for data interpretation. The use of a quantitative method was based on our conclusive product that requires a deductive conclusion for a hypothesis based on previous studies (i.e., the multilingual awareness) as mentioned in the introduction and the literature review. The quantitative data were represented mainly by the questionnaire and the two tests. The scores were our main concern due to their relevance to statistical analyses that relies only on numbers. The research sample mainly included students from Mutah University. The students answered a questionnaire and two tests. The questionnaire that was used to measure the multilingual level of the students is the LEAP-Q designed by Blumenfeld and Kaushanskaya (2007). The LEAP-Q is designed to measure many aspects of language related phenomena such as language dominance, language exposure, and language preference; suitable for ages 14 to 80; can be administered in three forms: orally (interview), pencil and paper, and digitally; and available in 31 languages. The LEAP-Q uses an 11-point (0-10) Likert scale to determine the degree of strength in its items with each point associated to a descriptive label. The proficiency TOEFL test focused mainly on the receptive skills of the participants: reading and listening. We disregarded the productive skills in the TOEFL test. Moreover, we included only one paragraph for reading and one audio for listening with 19 questions to be answered in 15 minutes. The critical thinking test focuses mainly on inferences, assumptions, deductions, conclusions, and interpreting arguments (Watson \& Glaser, 2009). It consists of 80 items to be answered in 60 minutes. However, we only included 18 items of the test to be answered in 15 minutes mainly focusing on assumptions, deductions, and interpreting information. The reason for using short versions of both tests (the TOEFL and the critical thinking tests) is that students had to finish all the measures -including the questionnaire- in one session. In such cases, it is well known that students will begin to feel the need to fill everything so quickly disregarding the researcher's need for authentic answers. As a result, we shortened the tests, but not the questionnaire, in order to get as much as honest and authentic answers as possible.

The sample for this research consisted of 52 students (aged between 20 and 26) enrolled in the bachelor program and majored in English language and literature at Mutah University in Jordan. The sample included 25 males and 27 females ranging from second year to fourth year. The participants' native language is Arabic. The selection of the students was based on the purpose of the study. We selected 2nd, 3rd, and 4th year students because 1st year students have had little experience in language training. Including 1st year students shows bias towards the national identity in which we are trying to eliminate. By eliminate, we are referring to eliminating the bias, not the national identity. The bias here is explained in terms of experience. In other words, the 1 st year students lack the experience of learning a second language on a wider scale, thus their attachment to their national identity is still at its maximum levels. 


\section{IRJE | Indonesian Research Journal in Education | | Vol. 5 | No. 1|June | Year 2021|}

\section{Data collection and analysis}

The students finished the questionnaire and the two tests in one session. The researchers of the study administrated the data collection session after the approval of the university and the attendance of the volunteers. The students were given the questionnaire first followed by the proficiency test and finished the critical thinking test last. The questionnaire was held at the university, done on computer devices, and administered to clarify all aspects of ambiguity (if there is any) in its items. The questionnaire is meant to measure how much and how often a multilingual speaker uses his/her languages on a daily basis. For the native language, it is clear that learners would almost have the same level. However, for the second language (i.e., English), the students varied considerably regarding language use. The varied patterns demonstrated by the students' answers are limited nonetheless. It seems that some advanced students (in terms of second language use) use English even at home but only in cases in which they watch a TV show or listen to music. This means that productive skills are only practiced in the classroom, whereas the receptive skills can be practiced anywhere.

We used Microsoft excel for computerizing the critical thinking test by having the questions automatically graded with the use of excel formulas. The LEAP-Q was already computerized on a Microsoft word file that can be transferred to Microsoft excel for dealing with numbers. The TOEFL test was also computerized on an excel sheet much like the critical thinking test with formulas for grading the subjects as they answer the questions. The two tests were also held at the university, done on computers, and administered to clarify ambiguity (if there is any) and eliminate any chances for cheating. Then the data was collected from the computers then imported to SPSS then analysed using Person's product coefficient for the correlation analysis. The analysis shows significant correlations amongst all three concepts (language use, proficiency and critical thinking).

It should be mentioned that Mutah University approved collecting data for the study without forcing subjects to participate in the study. The university administration informed the subjects in the English language department what kind of sample is required for the study and we also informed them that their data will be dealt with anonymously. The subjects were also told that their approval of participation is indicated in their attendance. In other words, if the subject attended the data collection session, his approval is implied.

\section{Findings}

Correlation analyses are commonly used to answer the "what" and the "how". The "what" refers to what kind of relationship exists between the variables: positive, negative, or no relationship. The "how" refers to how close or distant the relationship -if there is any- is. A relationship is positive when the variables show a one direction progression. In other words, when one of the variables goes up, the other variable also goes up. A relationship is negative when the variables show a different direction progression. In other words, when one variable goes up, the other variable goes down. The degree of closeness is measured with the correlation score which is limited to the numbers between 1 and 0 , or 0 and -1 . The 


\section{IRJE | Indonesian Research Journal in Education | | Vol. 5 | No. 1|June | Year 2021|}

closer the score to 1 , the higher positive correlation presented. The closer the score to -1 , the higher negative correlation presented. The closer the score to 0 , the weaker the correlation presented whether positive or negative and, in some instances, it presents no relationship. First, table 1.1 shows the correlation analysis test results on SPSS. The results indicate strong positive associations amongst the three variables (language use, linguistic competence, and critical thinking).

Table 1. Pearson's correlation analysis test results for language use, linguistic competence, and critical thinking

\begin{tabular}{llll}
\hline TOEFL score & $.678(\mathrm{p}=.000)$ & $.727(\mathrm{p}=.000)$ & 1 \\
Critical thinking & $.625(\mathrm{p}=.000)$ & 1 & \\
Multilingual level & 1 & & \\
\hline
\end{tabular}

Second, the relationship between language use and critical thinking is shown in figure 1 . The variables were found to be strongly correlated, $r(.625), \mathrm{n}=52, \mathrm{p}=0.000$.

Figure 1.The relationship between language use and critical thinking

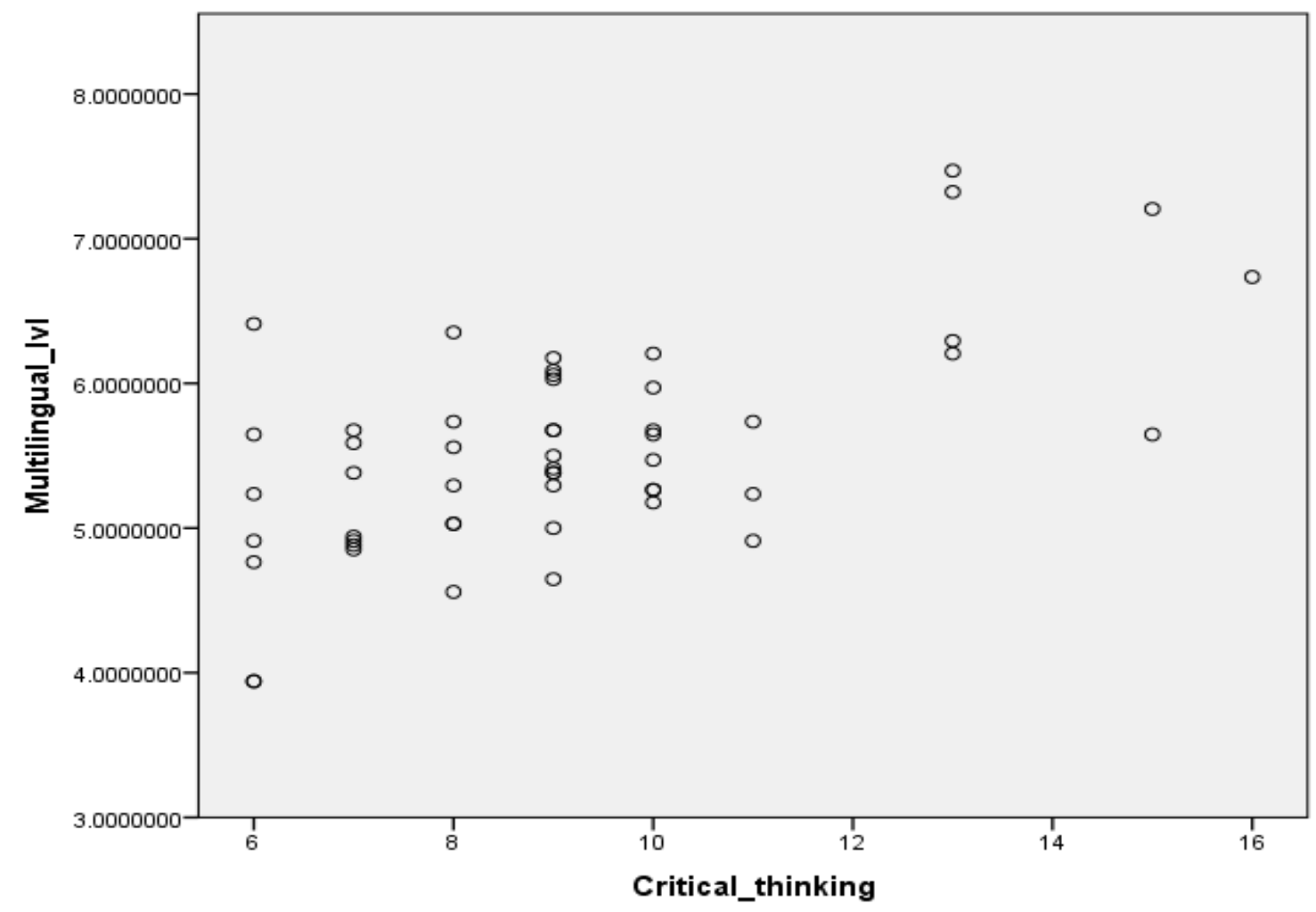

Third, the relationship between linguistic competence and critical thinking is shown in figure 2. The variables were found to be strongly correlated, $r(.72), \mathrm{n}=52, \mathrm{p}=0.000$. 
Figure 2. The relationship between linguistic competence and critical thinking

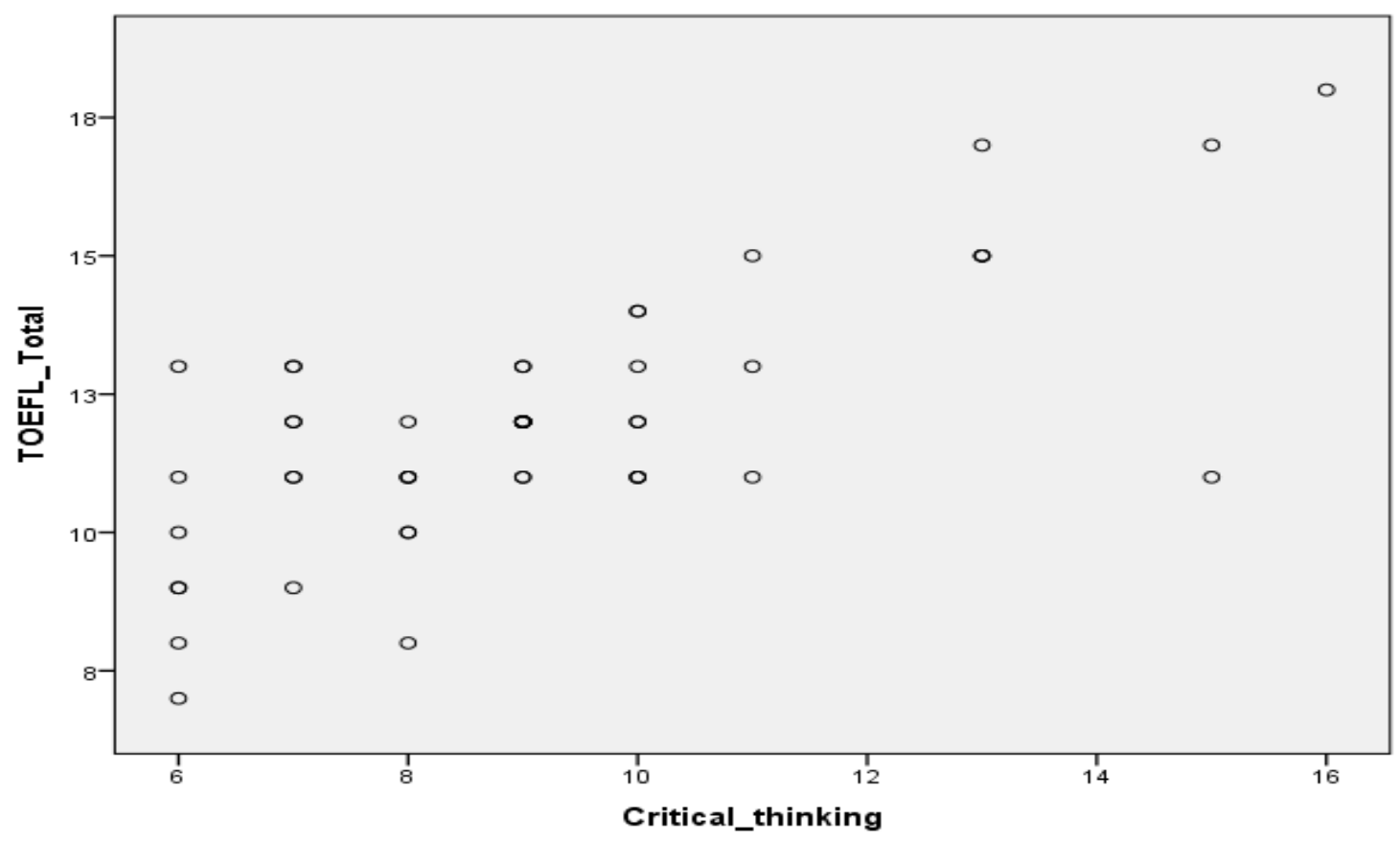

Finally, the relationship between language use and linguistic competence is shown in figure 3. The variables were found to be strongly correlated, $r(.67), \mathrm{n}=52, \mathrm{p}=0.000$.

Figure 3. The relationship between language use and linguistic competence

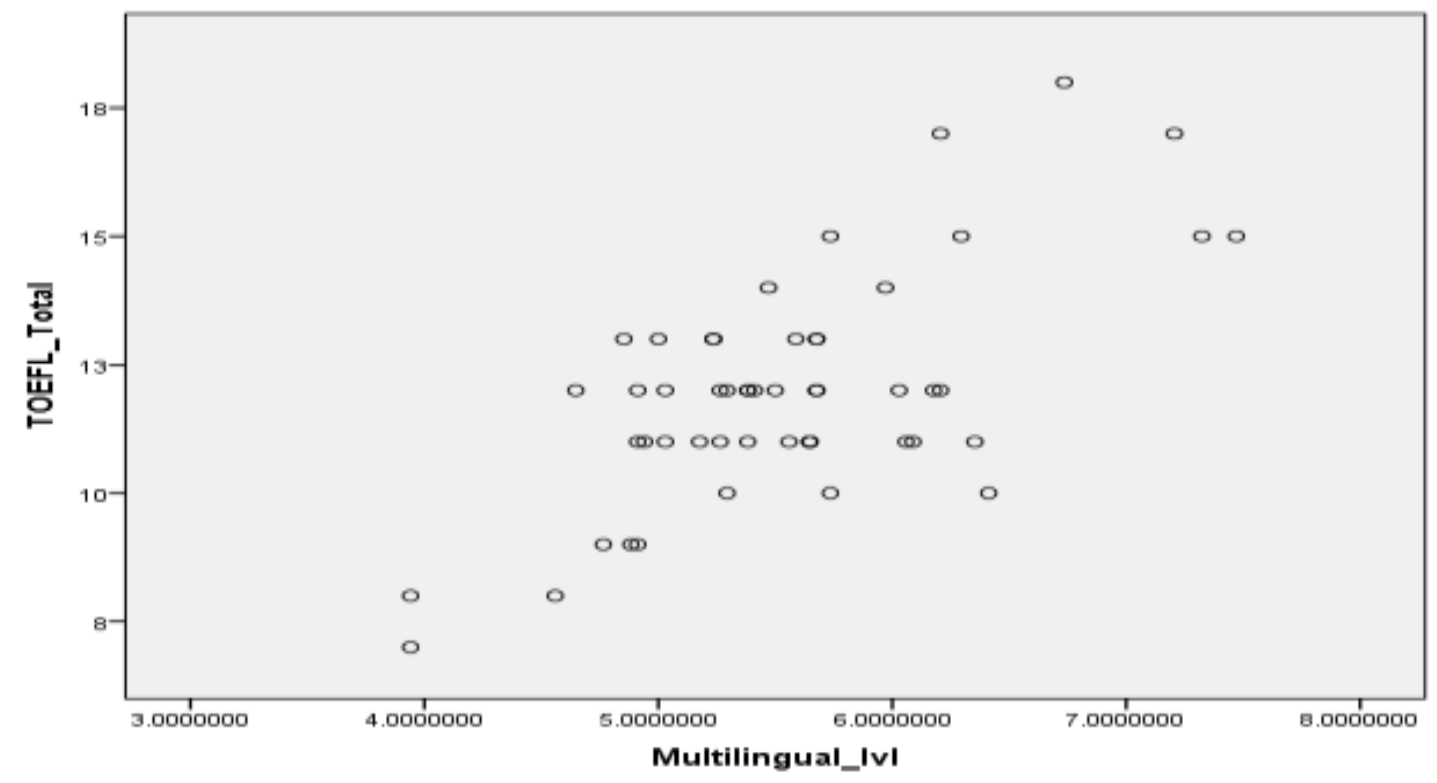




\section{IRJE | Indonesian Research Journal in Education | | Vol. 5 | No. 1|June | Year 2021|}

\section{Discussion}

The findings of this study demonstrate that language use, proficiency, and critical thinking are highly related. Figure 1 demonstrates the relationship between language use and critical thinking. The strong association between the two variables indicates that using more than one language in varying degrees seems to influence the cognitive abilities of the individuals. However, we cannot make that claim because the correlation analysis only shows the strength of the association rather than what or how variables influence each other. This means that either language use influences critical thinking, or that critical thinking influences language use. The unknown direction of causality leads us to conclude that critical thinking is a necessary component of language learning and teaching on one hand. The previous literature on classroom practices suggests that critical thinking is highly associated to language learning and language teaching (Shirkhani \& Fahim, 2011; Meiramova, 2017; Zhao, Pandian \& Singh, 2016). On the other hand, substantial research suggests a cognitive advantage for multilinguals over monolinguals (Alladi et al., 2013; Bialystok et al., 2007; Kirk, et al., 2013). Some of these studies focused on cognitive decline amongst monolinguals and multilinguals to find that multilinguals develop dementia significantly later than monolinguals (Alladi et al., 2013; Bialystok et al., 2007). These studies reported a significant delay in the onset age of dementia in favor of multilinguals. Other studies focused on other forms of cognition such as executive functioning and inhibitory control in specific (Bialystok et al., 2004; Kirk et al., 2013). Mixed results have been reported. Bialystok et al. (2004) reported a cognitive advantage in the Simon task having found multilinguals to react faster than monolinguals. Kirk et al. (2013), on the other hand, has not reported such an advantage having found no significant differences in reaction time between multilinguals and monolinguals in the Simon task. Moreover, critical thinking includes skills such as problem solving, making inferences, making decisions, think reasonably, and think logically amongst other skills. These skills can be applied in social settings when conversing with others. Bagheri (2015), for instance, argues that applying critical thinking skills in the language learning process seems to influence the learners' choices regarding the learning strategy use. In other words, learners who apply critical thinking skills seem to choose a variety of learning strategies that fit their learning style. The fact that critical thinkers could use different strategies for learning also means that they could use different strategies for conversations in social settings to show interest, raise awareness of the topic, organize thought, repair breakdowns, etc. This means that critical thinkers could fit better in social settings and that might explain why the critical thinking score significantly and highly correlated to language use. However, the case could be the opposite when the use of conversation strategies enhances the cognitive abilities of individuals given that these strategies are not learnt but applied immediately due to a prior experience (i.e., the first language conversation strategies). Applying these strategies for a new language could prove to be useful for cognition.

Figure 2 demonstrates the relationship between linguistic competence and critical thinking. As mentioned earlier, Bagheri (2015) argues that successful language learners are equipped with better critical thinking skills. So, it seems plausible to suggest that the teaching 


\section{IRJE | Indonesian Research Journal in Education | | Vol. 5 | No. 1|June | Year 2021|}

of critical thinking skills must become common in schools. However, we still cannot claim that critical thinking influences language learning due to the correlation analysis which does not show the direction of causality. Perhaps proficiency affects the critical thinking abilities of the individual. Bagheri (2015) herself states that students who received EAP (English for academic purposes) training showed better critical thinking skills. Moreover, Bauer, Holmes and Warren (2006) argue for the same direction as Bagheri (2015). Bauer, Holmes and Warren (2006) suggested that better linguistic abilities are crucial in accomplishing better critical thinking abilities. Regardless of the direction of causality, critical thinking is a very important aspect of teaching and learning. Teachers need critical thinking abilities to enhance their teaching experience whereas students need critical thinking abilities to enhance their learning experience. Students should be taught to think critically and demonstrate high order skills and abilities. These skills and abilities will not only aid them in language learning only, but also aid them in learning in general. In a pilot study conducted with the Watson and Glaser critical thinking test, Lombard and Grosser (2008) argued that the quality of teaching critical thinking needs to improve for teachers in order to pass it on to their students properly. However, our aim in this study is to argue for multilingualism and linguistic competence as influential factors on cognition. The fact that linguistic use and linguistic competence both correlated significantly to critical thinking provides empirical support to our claims. It is evident at this point that confusion arises to the surface because of the different perspectives on critical thinking and language proficiency. On one hand, some argue that critical thinking is crucial for language learning. On the other hand, others argue for language proficiency as a crucial aspect of developing critical thinking. To sum up this part, teaching critical thinking and language teaching always go hand in hand because the two seem to influence each other in varying degrees. Moreover, critical thinking is very important for both learners and teachers, but seems a bit more important for learners. Whereas teachers rely more on experience in classrooms, learners rely more on cognitive acts inside and outside the classroom (e.g. paying attention for comprehension, memorizing, studying, revising, taking notes while listening, etc.).

Figure 3 shows the relationship between language use and linguistic competence. This phenomenon is well known in common circumstances. The more one uses a language, the more one becomes proficient in that language. Dewey et al. (2012), for instance, reported that time spent in Japan, time spent speaking Japanese, time spent speaking Japanese with native speakers, and dispersion (number of social groups in which a learner participated) are good predictors of language proficiency for non-native speakers of Japanese who studied in Japan. When learners decide to use the language more frequently, they gain better knowledge and control over time. They gain knowledge regarding the many aspect of the language being learnt including grammar and vocabulary. They also gain control over the grammar of the spoken language in the sense that learners will eventually find better opportunities to apply grammatical constraints on the stream of strings in conversations. Even in pragmatics (i.e. knowledge of the social conduct of conversations) learners will gain more knowledge and control over time. They will learn when and how to apply certain forms of language in certain social settings. However, it is not yet clear if teachers in foreign settings (settings where the second language is not spoken) build better linguistic knowledge on the basis of language use in the classroom. Theoretically, language use in foreign settings should enhance 


\section{IRJE | Indonesian Research Journal in Education | | Vol. 5 | No. 1|June | Year 2021|}

the teachers' linguistic experience. This assumption is based on the fact that teachers nowadays need background knowledge about certain topics. This need forces teachers to prepare well before the lesson, which means that teachers need to collect background knowledge either by reading about the topic or listening to a show (or a video) about the topic. In both cases (reading or listening), teachers will expand their knowledge and enhance their learning experience about both, the language and the topic that they are teaching.

To sum up, the need to enhance the language learning experience is evident in most scenarios nowadays due to the lack of interest in most cases by students. In Jordan, at least, it is well known that English is rarely spoken in public and only English language students speak English, but they rarely do so in public. The students' use of the English language is limited to the classroom in most cases. Enhancing language learning requires encouraging students to speak the second language outside the classroom to build a cognitive base that relies on using learning strategies for learning new aspects of the language and using conversational strategies for passing the nature of the social conducts of conversations to others (especially those who are still beginners in language learning). It is evident in previous studies that multilingualism provides a cognitive advantage for multilinguals. So, we can assume -but not confirm- that frequent language use should also enhance the higher order skills of the learners including their critical thinking skills.

\section{Conclusions}

The findings of this research indicate that strong relationships exist between language use, linguistic competence, and critical thinking. However, the unknown direction of causality makes it a bit difficult to conclude that multilingualism and proficiency are influential factors for enhancing critical thinking. In order to detect the direction of causality in correlational studies, a longitudinal study must be conducted with two groups. This research can be considered a good reference point for anyone who wants to investigate the effect of proficiency on critical thinking. This can be done by conducting a longitudinal research in which two groups (experimental and control group) are compared against each other. The experimental receives extensive training in a second language; the other group receives basic training in a second language to see if extensive training enhances the critical thinking of the experiment group compared to the control group. The same can be said about language use but with a different method. For instance, a group of L2 learners in foreign settings compared to L2 learners in native settings. Most research on critical thinking claims that teaching critical thinking will enhance the learners' ability to learn a second language (Rezaei, et al., 2011; Shirkhani, \& Fahim, 2011). These claims are supported by the results of this study given that the strongest association is reported between critical thinking and linguistic competence. However, little or no reports had been provided on the impact of language use on critical thinking. The multilingual level of individuals determined by their use of the language being learned could prove to be efficient in enhancing their cognitive abilities. If so, trends to encourage speaking the second language in foreign settings must arise. If speaking in public is not to occur, then another trend should arise to address the issue of teaching critical thinking and especially in Jordan. This call comes from the fact that the Jordanian courses at the university level do not include a plan to teach critical thinking in 


\section{IRJE | Indonesian Research Journal in Education | | Vol. 5 | No. 1|June | Year 2021|}

an explicit or an implicit manner. Students need critical thinking for cases, the university level learning, and real-life preparation.

\section{Disclosure statement}

No potential conflict of interest was reported by the authors of this manuscript.

\section{References}

Alladi, S., Bak, T. H., Duggirala, V., Surampudi, B., Shailaja, M., Shukla, A. K., ... \& Kaul, S. (2013). Bilingualism delays age at onset of dementia, independent of education and immigration status. Neurology, 81(22), 1938-1944.

Bagheri, F. (2015). The relationship between critical thinking and language learning strategies of EFL learners. Journal of Language Teaching and Research, 6(5), 969-975.

Bailin, S. (2002). Critical thinking and science education. Science \& Education, 11(4), 361-375.

Bauer, L., Holmes, J., Warren, P., \& Warren, P. (2006). Language matters. New York: Palgrave Macmillan.

Bhatia, T. K. (2013). Bilingualism and multilingualism. Retrieved on October 20, 2017 from https://wwwoxfordbibliographies.com/view/document/060-97

Bialystok, E., Craik, F. I., \& Freedman, M. (2007). Bilingualism as a protection against the onset of symptoms of dementia. Neuropsychologia, 45(2), 459-464.

Bialystok, E., Craik, F. I., Klein, R., \& Viswanathan, M. (2004). Bilingualism, aging, and cognitive control: Evidence from the Simon task. Psychology and aging, 19(2), 290.

Bloom, B. S. (1956). Taxonomy of educational objectives: The classification of educational goals. New York: David McKay Company, Inc.

Bloom, B.S., Engelhart, M.D., Furst, E.J., Hill, W.H., \& Krathwohl, D.R. (1956). Taxonomy of education objectives book 1: Cognitive Domain. New York: David McKay Company, Inc.

Burden, P.R., \& Byrd, D.M. (1994). Methods for effective teaching. Boston, MA: Allyn and Bacon, Inc.

Case, R. (2005). Moving critical thinking to the main stage. Education Canada, 45(2), 45-49.

Cook, Vivian. (2005). Who is the L2 user? Multi-competence and foreign language learning/teaching. Retrieved on December 2017 from http://www.viviancook.uk/Writings/Papers/Kochi2010.htm

Cottrell, S. (2017). Critical thinking skills: Effective analysis, argument and reflection. Macmillan International Higher Education.

de Bot, Kees. (2017). The Future of the Bilingual Advantage. Future Research Directions for Applied Linguistics. Bristol: Blue Ridge Summit.

Dewey, D. P., Bown, J., \& Eggett, D. (2012). Japanese language proficiency, social networking, and language use during study abroad: Learners' perspectives. Canadian Modern Language Review, 68(2), 111-137.

Ennis, R.H. (1962). A concept of critical thinking. Harvard Educational Review, 32(1), 81-111.

Ennis, R. H. (1985). A logical basis for measuring critical thinking skills. Educational Leadership, 43(2), 44-48. 


\section{IRJE | Indonesian Research Journal in Education | | Vol. 5 | No. 1|June | Year 2021|}

Ennis, R. H. (1989). Critical thinking and subject specificity: Clarification and needed research. Educational Researcher, 18(3), 4-10.

Fábián, G. (2015). The conceptual framework of critical thinking in education: a proposal. Towards New Approaches to Scientific Inquiry: Interdisciplinarity in the 21st Century, 446-461.

Fábián, G. (2018). Reasons for non-critical thinking: The multilevel model approach. New Trends and Issues Proceedings on Humanities and Social Sciences, [Online]. 5(3), 077-083. (PDF) Reasons for non-critical thinking: The multilevel model approach.

Facione, P. A. (1990). Critical thinking: A statement of expert consensus for purposes of educational assessment and instruction. Millbrae, CA: The California Academic Press.

Facione, P. A. (2000). The disposition toward critical thinking: Its character, measurement, and relation to critical thinking skill. Informal Logic, 20(1), 61-84.

Halpern, D. F. (1996). Thinking critically about critical thinking. Routledge.

Halpern, D. F. (1998). Teaching critical thinking for transfer across domains: Dispositions, skills, structure training, and metacognitive monitoring. American Psychologist, 53(4), 449-455.

Halpern, D. F. (2001) Assessing the effectiveness of critical thinking instruction. The Journal of General Education, 50(4), 270-286.

Herina, P., \& Jessner, U. (2000). Multilingualism as an ecological system. The case for language maintenance. na.

Jessner, Ulrike. (2008). Teching third languages: Findings, trends and challenges Ulrike Jessner University of Innsbruck, Austria. Retrieved on November 25, 2017 from Ulrike.Jessner@,uibk.ac.athttps://www.unil.ch/files/live/sites/magicc/files/shared/ Ressources/Jessner 2008 Teaching third languages.pdf

Jessner, U., \& Török, V. (2017). Strategies in multilingual learning: Opening new research avenues. Future Research Directions for Applied Linguistics. Bristol: Blue Ridge Summit.

Kennedy, M., Fisher, M. B., \& Ennis, R. H. (1991). Critical thinking: Literature review and needed research. In L. Idol \& B.F. Jones (Eds.), Educational values and cognitive instruction: Implications for reform (pp. 11-40). Hillsdale, New Jersey: Lawrence Erlbaum \& Associates.

Kirk, N., Scott-Brown, K., \& Kempe, V. (2013). Do older Gaelic-English bilinguals show an advantage in inhibitory control?. In Proceedings of the Annual Meeting of the Cognitive Science Society, 35(35).

Koenig, M. A., \& Harris, P. L. (2005). Preschoolers mistrust ignorant and inaccurate speakers. Child Development, 76(6), 1261-1277.

Kuhn, D. (1999). A developmental model of critical thinking. Educational Researcher, 28(2), 16-26.

Lewis, A., \& Smith, D. (1993). Defining higher order thinking. Theory into Practice, 32(3), 131137.

Lombard, K., \& Grosser, M. (2008). Critical thinking: are the ideals of OBE failing us or are we failing the ideals of OBE?. South African journal of education, 28(4), 561-580.

Lutz, D. J., \& Keil, F. C. (2002). Early understanding of the division of cognitive labor. Child Development, 73(4), 1073-1084. 


\section{IRJE | Indonesian Research Journal in Education | | Vol. 5 | No. 1|June | Year 2021|}

Marian, V., Blumenfeld, H. K., \& Kaushanskaya, M. (2007). The language experience and proficiency questionnaire (LEAP-Q): Assessing language profiles in bilinguals and multilinguals. Journal of Speech, Language, and Hearing Research, 50(4), 940-967.

Martinez, M. E. (2006). What is metacognition? Phi Delta Kappan, 87(9), 696-699.

Meiramova, S. (2017). Applications of critical thinking research: Foreign language teaching in an intercultural context. The Online Journal of New Horizons in Education-January, 7(1).

Nickerson, R. S. (1988). On improving thinking through instruction. Review of Research in Education, 15(1988-1989), 3-57.

Nixon, G. (2013). Why are metalinguistic skills important? Retrieved on January from http://www.gemmlearning.com/blog/learning-issues/why-are-metalinguistic-skills-i mportant/

Pascarella, E., \& Terenzini, P. (1991). How college affects students: Findings and insights from twenty years of research. San Francisco, CA: Jossey Bass.

Paul, R. (1992, a). Critical thinking: What every person needs to survive in a rapidly changing world (2nd ed.). Santa Rosa, CA: The Foundation for Critical Thinking.

Paul, R. W. (1992, b). Critical thinking: What, why, and how? New Directions for Community Colleges, 1992(77), 3-24.

Rezaei, S., Derakhshan, A., \& Bagherkazemi, M. (2011). Critical thinking in language education. Journal of Language Teaching and Research, 2(4), 769.

Shirkhani, S., \& Fahim, M. (2011). Enhancing critical thinking in foreign language learners. Procedia-Social and Behavioral Sciences, 29, 111-115.

Simon, H.A., \& Kaplan, C.A. (1989). In Posner, M.I. (Ed), Foundations of cognitive sciences. (pp. 1-47). Cambridge, MA: MIT Press.

Stahl, N.N., \& Stahl, R.J., (1991). We can agree after all: Achieving a consensus for a critical thinking component of a gifted program using the Delphi technique. Roeper Review, 14(2), 79-88.

Sternberg, R. J. (1986). Critical thinking: Its nature, measurement, and improvement. National Institute of Education. Retrieved from http://eric.ed.gov/PDFS/ED272882.pdf.

Watson, G. \& Glaser, E.M. (2009). Watson-Glaser II Critical Thinking Appraisal technical manual and user's guide. San Antonio, TX: Pearson.

Willingham, D. T. (2007). Critical thinking: Why is it so hard to teach? American Educator, 819.

Zhao, C., Pandian, A., \& Singh, M. K. M. (2016). Instructional strategies for developing critical thinking in EFL classrooms. English Language Teaching, 9(10), 14-21.

\section{Biographical notes}

HAZIM TAISIR DAYIJ ALKHRISHEH is a PhD student at Multilingualism Doctoral School, the University of Pannonia, Hungary; hkhresha@yahoo.com

FAILASOFAH is PhD student at Multilingualism Doctoral School, the University of Pannonia, Hungary and Faculty member at Faculty of Teacher Training and Education, Universitas Jambi, Jambi, Indonesia;t failasofah@unja.ac.id

TAISIR ALKHRISHEH works at Amman Arab University, Jordan; tkhrisheh@yahoo.com 